\title{
Multi-scale Modeling of Structure, Dynamic and Thermodynamic Properties of Imidazolium-based lonic Liquids: Ab initio DFT Calculations, Molecular Simulation and Equation of State Predictions
}

\author{
I.G. Economou ${ }^{1,2^{*}}$, E.K. Karakatsani ${ }^{1}$, G.-E. Logotheti ${ }^{* *}$, J. Ramos ${ }^{3}$ and A.A. Vanin ${ }^{4}$ \\ 1 Molecular Thermodynamics and Modeling of Materials Laboratory, Institute of Physical Chemistry, National Center for Scientific Research \\ "Demokritos", 15310 Aghia Paraskevi Attikis - Greece \\ 2 Center for Phase Equilibria and Separation Processes (IVC-SEP), Department of Chemical Engineering, Technical University of Denmark, \\ 2800 Lyngby - Denmark \\ 3 Department of Macromolecular Physics, Instituto de Estructura de la Materia - CSIC, Serrano 113 bis, 28006, Madrid - Spain \\ 4 Department of Chemistry, Saint Petersburg State University, Universitetsky prospect 26, Stariy Petergof, 198504, Saint Petersburg - Russia \\ e-mail: economou@chem.demokritos.gr \\ * Corresponding author \\ ** Current address: Hyperion Systems Engineering Ltd., 41-43 Agiou Nicolaou street, 2408 Nicosia - Cyprus
}

\begin{abstract}
Résumé - Modélisation multi-échelle de la structure et des propriétés dynamiques et thermodynamiques de liquides ioniques à base d'imidazolium : Calculs ab initio DFT, simulation moléculaire et prédictions d'équation d'état - Les liquides ioniques ont fait l'objet d'une attention considérable de la part de l'industrie chimique au cours des dernières années, surtout du fait du développement de procédés respectueux de l'environnement. Dans ce travail, la structure microscopique et les propriétés dynamiques et thermodynamiques des liquides ioniques à base d'imidazolium sont calculées en utilisant des modèles théoriques qui couvrent un éventail d'échelles de temps et de longueur, des calculs ab initio sur la base de la théorie de densité fonctionnelle (DFT) à la simulation moléculaire atomistique et finalement à une équation macroscopique d'état basée sur la théorie de perturbation. Différents liquides ioniques et solvants polaires sont examinés et les calculs sont exécutés sur une large gamme de conditions. Les résultats de la modélisation sont comparés avec les données expérimentales de littérature. Dans tous les cas, la correspondance entre l'expérience et les calculs/la théorie est très bonne. Ainsi, il est vérifié que des modèles, soigneusement choisis, peuvent être employés pour l'évaluation fiable de propriétés, même en absence de mesures expérimentales.
\end{abstract}

Abstract - Multi-scale Modeling of Structure, Dynamic and Thermodynamic Properties of Imidazolium-based Ionic Liquids: Ab initio DFT Calculations, Molecular Simulation and Equation of State Predictions - Ionic liquids have received considerable attention by the chemical industry in recent years, mostly towards the development of environmentally benign processes. In this work, microscopic structure, dynamic and thermodynamic properties of imidazolium-based ionic liquids are calculated using theoretical models that cover a wide range of length and time scales, from ab initio density functional theory (DFT) calculations to atomistic molecular simulation and finally to a macroscopic equation of state based on perturbation theory. Different ionic liquids and polar solvents 
are examined and calculations are performed over a wide range of conditions. Model calculations are compared against literature experimental data. In all cases, the agreement between experiment and calculations/theory is very good. Thus, it is verified that carefully selected models can be used for reliable estimation of properties, even in the absence of experimental measurements.

\section{INTRODUCTION}

Over the last decade, ionic liquids (ILs) have received much attention for use as environmentally benign reaction and separation media [1-4]. ILs are molten salts with melting points close to room temperature. Their most remarkable property is that their vapor pressure is negligibly small, which means that ILs are non-volatile, non-flammable and odorless. Other characteristics of ILs include a wide liquid temperature range, a high thermal and electrochemical stability, a high ionic conductivity and good solvency properties. In principle, ILs can be tailored for a specific application by the right choice of cation and anion.

It is expected that ILs may revolutionize the chemical process industry in the years to come. Tentative applications include use of ILs as solvents in organic chemistry, in electrochemistry, as catalysts or as extracting agents for organic or ionic solutes. For example, they are increasingly used as novel processing media in combination with supercritical carbon dioxide $\left(\mathrm{CO}_{2}\right)$. Due to the negligible vapor pressure, it is possible to extract organic products from ILs using supercritical $\mathrm{CO}_{2}$ without any contamination by the IL [5-7]. Subsequently, this separation step can be combined with homogeneously catalyzed reactions in $\mathrm{IL} / \mathrm{CO}_{2}$ biphasic solutions, where the catalyzed reaction takes place in the IL phase and the product can be separated by extraction into the $\mathrm{CO}_{2}$ phase [8-13]. Further process development requires data on vapor-liquid equilibria (VLE) of mixtures of ILs and $\mathrm{CO}_{2}$. In parallel, aqueous IL mixtures are very important for a number of chemical processes. A critical parameter here is whether water and IL are fully miscible or a liquid-liquid equilibrium (LLE) region occurs. In the latter case, solute molecules partition between the two phases and so a relevant separation process should be designed.

As it becomes clear, development of new processes based on ILs requires accurate knowledge of the physical properties of the pure ILs but also of the IL mixtures involved. Furthermore, the microscopic structure of the fluid controls, to a large extent, the macroscopic properties and thus its detailed description is desirable as well. In the past few years, a growing number of experimental studies of thermodynamic properties of pure ILs and IL mixtures have been reported [14-23]. Despite the wealth of data available, more data are needed for process design, and their experimental determination is often difficult, time-consuming and expensive. Therefore, it is highly desirable to develop predictive methods for estimating the relevant properties.
At the molecular level, early molecular simulation studies focused on the development of accurate quantum mechanics derived force-fields and their validation towards the prediction of structure and thermodynamic properties of ILs in melt [24-26]. Both all-atom and united-atom models were used. Subsequent work concentrated on the simulation of solubilities of gases (such as $\mathrm{CO}_{2}, \mathrm{CO}$, etc.) and water in IL [27-29]. In most cases, imidazolium-based ILs were examined, which are considered as first-generation ILs. Furthermore, structural characteristics such as weak Lewis acid-base and hydrogen bonding interactions between $\mathrm{IL}$ and $\mathrm{CO}_{2}$ or water molecules were investigated [29].

Equations of state (EoS) have been also used for modeling the ILs phase behavior with various solvents. Most efforts have been restricted to low and medium pressure and applications to high pressures are limited. In most cases, cubic EoS including Redlich-Kwong and Peng-Robinson EoS have been used with multiple adjustable parameters. Furthermore, binary IL - water systems (LLE) have been modeled using the NRTL EoS [30] and excess Gibbs energy methods [31]. Ternary IL - alcohol - alkane systems have been modeled using the UNIQUAC EoS [32]. All these approaches invoke a large empiricism with relatively limited predictive capability. A suitable predictive model should account explicitly for the various molecular features that characterize IL mixtures. For example, there is experimental and molecular simulation evidence that there is strong association between $\mathrm{CO}_{2}$ acting as a Lewis acid and the anion of an IL acting as a Lewis base. Huang et al. [29] claimed that this association is due to the strong charge-quadrupole moment interaction between $\mathrm{CO}_{2}$ and the anions. On the other hand, fully dissociated IL molecules in water are expected to be solvated. Such phenomena can be modeled accurately using models with strong theoretical background.

In this paper, a multi-scale computational framework is presented for the accurate prediction of microscopic structure and macroscopic physical properties of ILs in pure state and in mixture. Calculations are restricted to imidazolium-based ILs, although the models are generally applicable to different families of ILs. Ab initio Density Functional Theory (DFT) calculations are performed on isolated IL molecules in order to evaluate the minimum energy structure and calculate charge density distribution of the molecule. Molecular dynamics (MD) simulations are performed on bulk IL at various temperatures and pressures using an atomistic force field with partial charges obtained from the DFT calculations. Volumetric and dynamic properties together with structure properties are reported. 
Molecular conformations from MD simulations are in good agreement with DFT results. The IL configurations generated from MD are used subsequently for the calculation of excess chemical potential, and thus solubility, of $\mathrm{CO}_{2}$ in the IL using the Widom test particle insertion methodology.

Although MD calculations are accurate, they are relatively time consuming. For engineering calculations, an EoS is preferred. In the last part of this paper, calculations from the truncated Perturbed Chain - Polar Statistical Associating Fluid Theory (tPC-PSAFT) $[33,34]$ are presented for IL binary and ternary mixtures. Strengths and limitations of the current model are discussed. All of the calculations presented here are compared against literature experimental data. The agreement between calculations and experiments is, in general, very good.

\section{AB INITIODFT CALCULATIONS}

All energies and geometries were calculated using the B3LYP hybrid DFT method as implemented in Gaussian03 [35]. This method consists of two different functionals: the Becke-3 parameter hybrid exchange functional [36] and the Lee-Yang-Parr correlation functional [37]. Both potentials use non-local exchange-correlation corrections for the density. The electronic configurations of the atoms were described by $6-311+\mathrm{G}^{*}$ basis set.

Atomic charges of different ionic pair conformers were calculated by electrostatic surface potential fits, using the CHelpG procedure [38], to electron densities obtained at B3LYP/6-311+G* level. Estimations for the atomic charges of the 1-butyl-3-methylimidazolium bis(triflouromethylsulfonyl) imide $\left(\left[\mathrm{bmim}^{+}\right]\left[\mathrm{Tf}_{2} \mathrm{~N}^{-}\right]\right)$and 1-hexyl-3-methylimidazolium bis(triflouromethylsulfonyl)imide $\left(\left[\mathrm{hmim}^{+}\right]\left[\mathrm{Tf}_{2} \mathrm{~N}^{-}\right]\right)$ ionic pairs have not been reported in the literature so far.

In addition, the electrostatic potential mapped on the electronic density was calculated on the isolated $\left[\mathrm{hmim}^{+}\right]$cation and $\left[\mathrm{Tf}_{2} \mathrm{~N}^{-}\right]$anion in order to find the most positive and negative areas for both species. Different initial guess conformations for the $\left[\mathrm{bmim}^{+}\right]\left[\mathrm{Tf}_{2} \mathrm{~N}^{-}\right]$and $\left[\mathrm{hmim}^{+}\right]\left[\mathrm{Tf}_{2} \mathrm{~N}^{-}\right]$compounds were prepared by matching the most positive areas of the cation with the more negative in the anion. Then, initial geometries were optimized using the B3LYP/6-311+G* method described above. The vibrational analyses on all structures revealed a lack of imaginary frequencies confirming the presence of true minima on the potential energy surface.

Parallel DFT calculations were carried out on R14000 at $600 \mathrm{MHz}$ multiprocessor Silicon Graphics workstation with 126 Gbytes of shared memory.

\section{MOLECULAR SIMULATION DETAILS}

MD simulations were performed for $\left[\mathrm{bmim}^{+}\right]\left[\mathrm{Tf}_{2} \mathrm{~N}^{-}\right]$and $\left[\mathrm{hmim}^{+}\right]\left[\mathrm{Tf}_{2} \mathrm{~N}^{-}\right]$over a wide temperature and pressure range.
Initial configurations for simulations were based on molecular conformations generated by the $a b$ initio DFT calculations. The MAPS simulation platform of Scienomics was used for such purposes [39]. The initial system was relaxed using a conjugate gradient energy minimization procedure. Subsequently, MD simulations in the NPT ensemble were performed.

Both the energy minimization procedure and the MD simulations were performed using the NAMD simulation code, version 2.6 [40]. NAMD was chosen for these calculations as it contains a number of technical features that are important for this work. It uses a very efficient full electrostatics algorithm based on the Particle Mesh Ewald (PME) method, which takes the full electrostatic interactions into account. Furthermore, NAMD allows for multiple time stepping. The time step for the bonded interactions was $1 \mathrm{fs}$, the Lennard-Jones short-range non-bonded interactions and the full electrostatics were evaluated every $2 \mathrm{fs}$ and $4 \mathrm{fs}$, respectively. The temperature was controlled using Langevin Dynamics while the Nosé-Hoover barostat was used to control pressure. Potential tails were brought smoothly to zero using a switching function [40].

The force field employed was of the form:

$$
\begin{aligned}
& U=U_{\text {bonded }}+U_{\text {non-bonded }}=\sum_{\text {bonds }} k_{b}\left(b-b_{o}\right)^{2}+\sum_{\text {angles }} k_{\theta}\left(\theta-\theta_{o}\right)^{2} \\
& +\sum_{\text {dihedrals }} \sum_{n=1}^{4} k_{x}[1+\cos (n x+\delta)]+\sum_{\text {impropers }} k_{\psi}\left(\psi-\psi_{o}\right)^{2} \\
& +\sum_{i=1}^{N-1} \sum_{j>i}^{N}\left\{4 \varepsilon_{i j}\left[\left(\frac{\sigma_{i j}}{r_{i j}}\right)^{12}-\left(\frac{\sigma_{i j}}{r_{i j}}\right)^{6}\right]+\frac{q_{i} q_{j}}{4 \pi \varepsilon_{0} r_{i j}}\right\}
\end{aligned}
$$

where $b, \theta$ and $\psi$ denote bond length, bond angle and improper angle, respectively, while subscript $o$ denotes the equilibrium value, $\varepsilon$ and $\sigma$ correspond to the Lennard-Jones parameters, $q$ denotes the partial charge and $\varepsilon_{0}$ the permittivity in vacuum. All bonded and Lennard-Jones parameters were taken from CHARMM force field following the work of Maginn et al. [26, 41, 42] while for the electrostatic interactions the partial charges evaluated from the DFT calculations were used.

Simulations were performed at pressures ranging from 1 to $60 \mathrm{MPa}$ and temperatures ranging from 298 to $333 \mathrm{~K}$. The initial configurations were equilibrated for 1,000-5,000 ps, depending on the simulation conditions and the initial structure. Stabilization of the running average for the density and the various components of the energy was used as a criterion for equilibration. Configurations from the production stage of each simulation were recorded every 1 ps in order to track the motions which dominate the short-time segmental dynamics. Long MD simulations, on the order of 20-30 ns (depending on the IL), were performed in order to capture accurately the dynamics of the molecules. 
Configurations of pure ILs generated by MD were used subsequently for the calculation of the excess chemical potential, $\mu^{e x}$, of $\mathrm{CO}_{2}$ using Widom's test particle insertion methodology [43]. According to Widom, a $\mathrm{CO}_{2}$ molecule is inserted randomly in the IL and the interaction energy of the molecule inserted due to its interaction with the IL molecules, $U_{C O}$, is calculated. It turns out, that for the NPT statistical ensemble it is:

$$
\mu_{C O_{2}}^{e x}=\mu-\mu^{i g}=-\frac{1}{\beta}\left[\frac{\left\langle V\left\langle\exp \left(-\beta U_{C O_{2}}\right)\right\rangle_{W i d o m}\right\rangle_{N P T}}{\langle V\rangle_{N P T}}\right]
$$

where $V$ represents the system volume, $\beta$ is equal to $(k T)^{-1}, k$ and $T$ denote the Boltzmann constant and the absolute temperature, respectively.

The Henry's law constant $\mathrm{H}_{\mathrm{CO}_{2} \rightarrow \mathrm{IL}}$ of the $\mathrm{CO}_{2}$ in the IL can be easily calculated from the expression:

$$
H_{C O_{2} \rightarrow I L}=\frac{\rho_{I L}}{\beta} \lim _{x_{C O_{2}} \rightarrow 0}\left[\exp \left(\beta \mu_{C O_{2}}^{e x}\right)\right]
$$

Interactions of a $\mathrm{CO}_{2}$ molecule with the $\mathrm{IL}$ were simulated as a summation of short-range Lennard-Jones interactions and of Coulombic interactions between charges using the Ewald summation method. Two accurate three-site rigid models were used for $\mathrm{CO}_{2}$, namely TraPPE [44] and modified extended primitive model EPM2 [45]. The interaction parameters between a $\mathrm{CO}_{2}$ molecule and an IL molecule were calculated using the Lorentz-Berthelot combining rules without any binary parameter adjustment.

The Henry's law constant of $\mathrm{CO}_{2}$ in $\left[\mathrm{bmim}^{+}\right]\left[\mathrm{Tf}_{2} \mathrm{~N}^{-}\right]$was computed at 298, 308, 318, and $328 \mathrm{~K}$. At each temperature, 3001 uncorrelated configurations from the MD simulations of pure ILs were saved to disk. For each of these configurations, $6000 \mathrm{CO}_{2}$ "test" molecules were inserted at random positions and orientations, and the Henry's law constant was determined.

Error bars were determined from the fluctuations of block averages. One block average is the average over 6000 insertions of "test" molecules in one configuration. The relative errors are around 20\% which is a typical value for the Widom's test particle insertion method and is in accord with errors reported for the simulation of gas solubilities in IL $[27,28,46]$.

\section{TRUNCATED PERTURBED CHAIN-POLAR STATISTICAL ASSOCIATING FLUID THEORY (TPC-PSAFT) FOR IONIC LIQUIDS}

Statistical Associating Fluid Theory (SAFT) and its variations are used widely to model non-ideal fluid mixture thermodynamic properties. SAFT has a strong statistical mechanics background but, at the same time, has moderate complexity over cubic EoS. Furthermore, it accounts explicitly for molecular size differences, weak dispersion and strong associating interactions. Recently, the model was extended to account explicitly for polar interactions due to permanent dipole and quadrupole moments and induced polar interactions due to molecular polarizability $[33,34]$. For practical engineering calculations, a truncated version of the full scale polar model was developed without significant decrease in the accuracy, due to the introduction of an additional physically justified adjustable parameter. The so-called tPC-PSAFT is written in terms of the residual Helmholtz free energy, $a^{\text {res }}$, as:

$$
\begin{aligned}
& \frac{a^{\mathrm{res}}(T, \rho)}{R T}=\frac{a^{\mathrm{hs}}(T, \rho)}{R T}+\frac{a^{\text {chain }}(T, \rho)}{R T} \\
& +\frac{a^{\mathrm{assoc}}(T, \rho)}{R T}+\frac{a^{\mathrm{disp}}(T, \rho)}{R T}+\frac{a^{\mathrm{polar}}(T, \rho)}{R T}
\end{aligned}
$$

where hs, chain, assoc, disp, and polar account for hard sphere, chain formation, association, dispersion and polar interactions, respectively. The individual terms of Equation 4 can be found elsewhere [33] and are not repeated here. In addition, the model is extended to mixtures using straightforward mixing rules [34]. Pure component model parameters include the number of spherical segments per molecule, $m$, the close packed volume of the spherical segment, $v^{o o}$, the dispersion interaction energy per segment, $u / k$, and the effective polar interaction diameter, $\sigma_{p}$. For associating fluids (as for example water), the model contains two additional parameters, that are the energy of association between sites $A$ and $B, \varepsilon^{A B} / k$, and the volume of association, $\mathrm{\kappa}^{A B}$. For the case of ILs, $m$ is fitted to liquid density data over a wide temperature and pressure range and by restricting the vapor pressure to be very low, $u / k$ and $v^{o o}$ values are obtained from the individual values for the anion and the cation while $\sigma_{p}=1.4 \sigma$, where $\sigma$ is the diameter corresponding to $v^{o o}$ [47] For binary mixture calculations, a binary interaction parameter, $k_{i j}$, is fitted to experimental data.

\section{RESULTS AND DISCUSSION}

\subsection{DFT Calculations}

\subsubsection{Electrostatic Potential of Single lons}

The electrostatic potential mapped on electronic density for $\left[\mathrm{hmim}^{+}\right]$and for $\left[\mathrm{Tf}_{2} \mathrm{~N}^{-}\right]$is shown in Figure 1. Blue areas in $\left[\mathrm{hmim}^{+}\right]$represent the most positive electrostatic regions while red in $\left[\mathrm{Tf}_{2} \mathrm{~N}^{-}\right]$display the most negative ones. Ring atoms in between the two $\mathrm{N}$ atoms (CR and HR) are more electropositive than the other $\mathrm{C}$ and $\mathrm{H}$ atoms in the ring $(\mathrm{CW}$ and $\mathrm{HW}$ ). Atoms on the alkyl chain are considerably less positive that those in the ring. On the other hand, the most negative areas in the anion are concentrated in the oxygen and nitrogen atoms. It is expected that the negative regions of the anion are located close to the positive areas of the cation. 


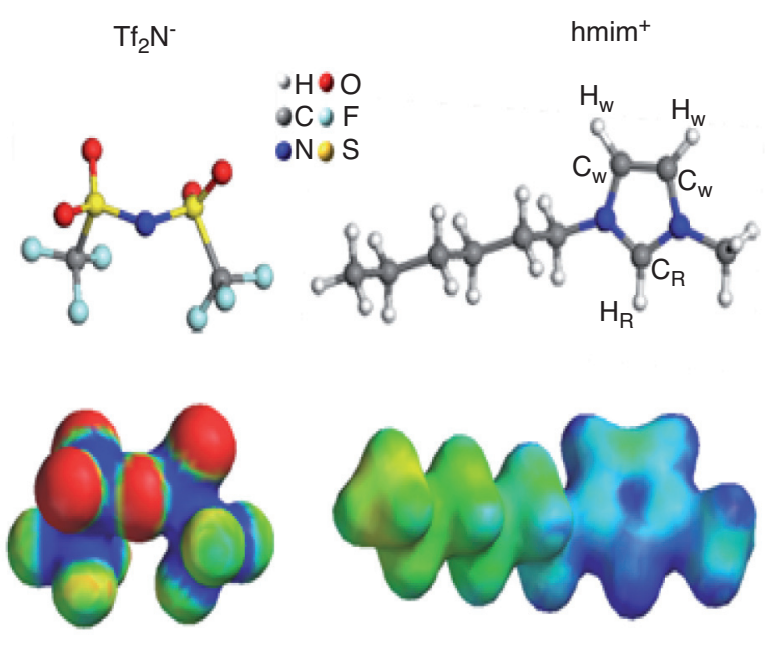

Figure 1

Electrostatic potential mapped on electronic density for $\left[\mathrm{hmim}^{+}\right]$cation and $\left[\mathrm{Tf}_{2} \mathrm{~N}^{-}\right]$anion at $\mathrm{B} 3 \mathrm{LYP} / 6-311+\mathrm{G}^{*}$. Isosurface value $0.02 \mathrm{e}$. Electrostatic potential ranges from $-80 \mathrm{kcal} / \mathrm{mol}$ (red) to $-30 \mathrm{kcal} / \mathrm{mol}$ (yellow) for $\left[\mathrm{Tf}_{2} \mathrm{~N}^{-}\right]$and from $20 \mathrm{kcal} / \mathrm{mol}$ (yellow) to $185 \mathrm{kcal} / \mathrm{mol}$ (blue) for $\left[\mathrm{hmim}^{+}\right]$.

\subsubsection{Geometries and Energies for $\left[\mathrm{bmim}^{+}\right]\left[\mathrm{Tf}_{2} \mathrm{~N}^{-}\right]$and $\left[\mathrm{hmim}^{+}\right]\left[\mathrm{Tf}_{2} \mathrm{~N}^{-}\right]$lon-Pairs}

Keeping in mind the above results, some different conformers were found for $\left[\mathrm{bmim}^{+}\right]\left[\mathrm{Tf}_{2} \mathrm{~N}^{-}\right]$and $\left[\mathrm{hmim}^{+}\right]\left[\mathrm{Tf}_{2} \mathrm{~N}^{-}\right]$ ion-pairs. The most stable conformers for both ion-pairs are displayed in Figure 2. Relative energies and selected geometrical parameters for isolated ions and for both ion-pairs are given in Table 1 . The conformers are characterized by a dihedral angle which indicates the relative orientation of the anion with respect to the cation $(\mathrm{X}-6 \mathrm{H}-33 \mathrm{~N}-30 \mathrm{~S}$ and $\mathrm{X}-6 \mathrm{H}-$ $39 \mathrm{~N}-36 \mathrm{~S}$ angles for $\left[\mathrm{bmim}^{+}\right]\left[\mathrm{Tf}_{2} \mathrm{~N}^{-}\right]$and $\left[\mathrm{hmim}^{+}\right]\left[\mathrm{Tf}_{2} \mathrm{~N}^{-}\right]$ respectively, in Figure 2, where $\mathrm{X}$ is the centroid of the imizadolium ring). A value of around $180^{\circ}$ indicates a perpendicular orientation of the anion with respect to the imidazolium ring, whereas values close to $0^{\circ}$ denote a parallel orientation. The I-III conformers for $\left[\mathrm{hmim}^{+}\right]\left[\mathrm{Tf}_{2} \mathrm{~N}^{-}\right]$ion-pair are very similar to each other, only slight differences are observed in the position of the anion with respect to the cation $\left(122.8^{\circ}, 164.0^{\circ}\right.$ and $141.6^{\circ}$ for $\mathrm{X}-6 \mathrm{H}-39 \mathrm{~N}-36 \mathrm{~S}$ angle, respectively). For the $\left[\mathrm{bmim}^{+}\right]\left[\mathrm{Tf}_{2} \mathrm{~N}^{-}\right]$ion-pair, only one conformer is found (137.1 $1^{\circ}$ for X-6H-33N-30S). In conformer V the anion is in a quasi-parallel orientation with respect to the imidazolium ring $\left(-0.8^{\circ}\right.$ and $14.2^{\circ}$ for $\left[\mathrm{bmim}^{+}\right]\left[\mathrm{Tf}_{2} \mathrm{~N}^{-}\right]$and $\left[\mathrm{hmim}^{+}\right]\left[\mathrm{Tf}_{2} \mathrm{~N}^{-}\right]$, respectively). In addition, they have the nitrogen atom of the anion pointing to the hydrogen atom $(6 \mathrm{H})$ of the cation. Nevertheless, in conformer IV both oxygen atoms from the anion $\left(32 \mathrm{O}\right.$ and $35 \mathrm{O}$ for $\left[\mathrm{bmim}^{+}\right]\left[\mathrm{Tf}_{2} \mathrm{~N}^{-}\right]$ and for $38 \mathrm{O}$ and $42 \mathrm{O}$ for $\left[\mathrm{hmim}^{+}\right]\left[\mathrm{Tf}_{2} \mathrm{~N}^{-}\right]$) are pointing out to the hydrogen atom $(6 \mathrm{H})$ giving shorter $\mathrm{O}-\mathrm{H}$ and longer $\mathrm{N}-\mathrm{H}$ distances than those observed for the conformer I-III and V. Conformers IV are slightly more stable than the others by aprox. $1.0 \mathrm{kcal} / \mathrm{mol}$ (see Table 1). Thus, we use the most stable conformers in the construction of the initial MD simulation boxes of the ionic liquids in the bulk phase. The electrostatic charges of the ion-pairs calculated by DFT/CHelpG

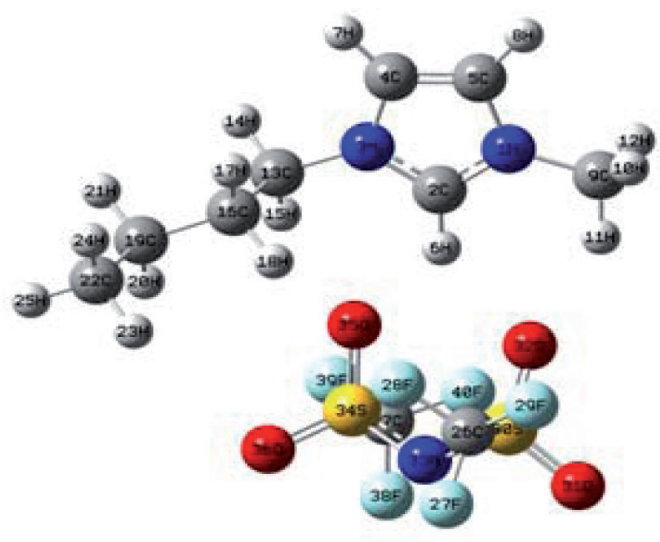

a)

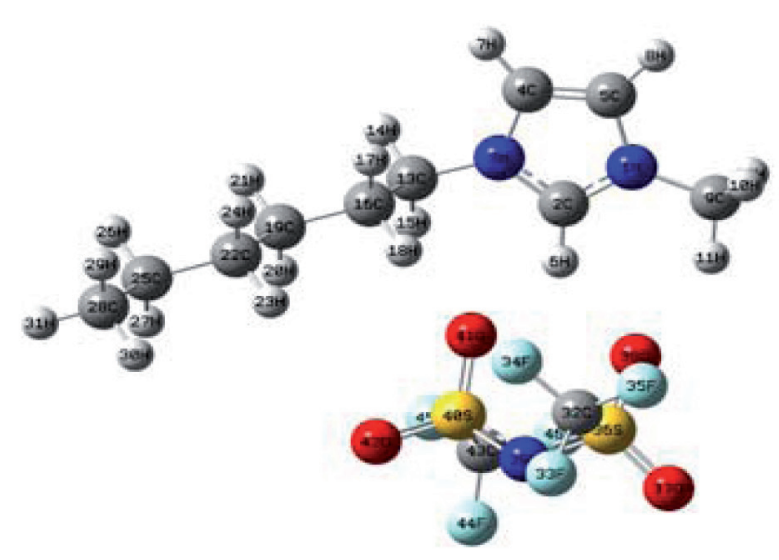

b)

Figure 2

Most stable conformers based on the DFT calculations for (a) $\left[\mathrm{bmim}^{+}\right]\left[\mathrm{Tf}_{2} \mathrm{~N}^{-}\right]$and (b) $\left[\mathrm{hmim}^{+}\right]\left[\mathrm{Tf}_{2} \mathrm{~N}^{-}\right]$ion pairs. 
TABLE 1

Selected geometrical parameters for DFT optimized $\left[\mathrm{bmim}^{+}\right]$, $\left[\mathrm{hmim}^{+}\right]$, $\left[\mathrm{Tf}_{2} \mathrm{~N}^{-}\right],[\mathrm{bmim}+]\left[\mathrm{Tf}_{2} \mathrm{~N}^{-}\right]$and $[\mathrm{hmim}+]\left[\mathrm{Tf}_{2} \mathrm{~N}^{-}\right]$structures. Numbering is assigned in Figure 2

\begin{tabular}{|c|c|c|c|c|c|}
\hline$\left[\mathrm{bmim}^{+}\right]$ & & & & & \\
\hline $6 \mathrm{H}-2 \mathrm{C}$ & 1.078 & - & - & - & - \\
\hline \multicolumn{6}{|l|}{$\left[\mathrm{hmim}^{+}\right]$} \\
\hline $6 \mathrm{H}-2 \mathrm{C}$ & 1.078 & - & - & - & - \\
\hline \multicolumn{6}{|l|}{$\left[\mathbf{T f}_{\mathbf{2}} \mathrm{N}^{-}\right]$} \\
\hline $33 N-30 S$ & 1.603 & - & - & - & - \\
\hline $33 \mathrm{~N}-34 \mathrm{~S}$ & 1.593 & - & - & - & - \\
\hline $30 \mathrm{~S}-310$ & 1.458 & - & - & - & - \\
\hline $30 \mathrm{~S}-32 \mathrm{O}$ & 1.457 & - & - & - & - \\
\hline $34 \mathrm{~S}-35 \mathrm{O}$ & 1.455 & - & - & - & - \\
\hline $34 \mathrm{~S}-36 \mathrm{O}$ & 1.457 & - & - & - & - \\
\hline$\left[\mathrm{bmim}^{+}\right]\left[\mathrm{Tf}_{2} \mathrm{~N}^{-}\right]$ & $\mathbf{I}$ & II & III & IV & $\mathbf{V}$ \\
\hline Energy & - & - & 0.00 & -0.94 & 0.67 \\
\hline $6 \mathrm{H}-33 \mathrm{~N}$ & - & - & 2.033 & 3.645 & 2.092 \\
\hline $6 \mathrm{H}-32 \mathrm{O}$ & - & - & 2.890 & 2.158 & 2.829 \\
\hline $6 \mathrm{H}-35 \mathrm{O}$ & - & - & 2.759 & 2.092 & 2.870 \\
\hline $6 \mathrm{H}-2 \mathrm{C}$ & - & - & 1.089 & 1.083 & 1.089 \\
\hline $33 N-30 S$ & - & - & 1.618 & 1.596 & 1.616 \\
\hline $33 \mathrm{~N}-34 \mathrm{~S}$ & - & - & 1.611 & 1.593 & 1.615 \\
\hline $30 \mathrm{~S}-310$ & - & - & 1.448 & 1.447 & 1.447 \\
\hline $30 \mathrm{~S}-32 \mathrm{O}$ & - & - & 1.463 & 1.470 & 1.463 \\
\hline $34 \mathrm{~S}-35 \mathrm{O}$ & - & - & 1.449 & 1.471 & 1.449 \\
\hline $34 \mathrm{~S}-36 \mathrm{O}$ & - & - & 1.464 & 1.448 & 1.463 \\
\hline $30 \mathrm{~S}-33 \mathrm{~N}-34 \mathrm{~S}$ & - & - & 127.8 & 128.5 & 127.7 \\
\hline $\mathrm{X}-6 \mathrm{H}-33 \mathrm{~N}-30 \mathrm{~S}$ & - & - & 137.1 & 76.4 & -0.8 \\
\hline \multicolumn{6}{|l|}{$\left[\mathrm{hmim}^{+}\right]\left[\mathrm{T}_{2} \mathrm{~N}^{-}\right]$} \\
\hline Energy & 0.08 & 0.04 & 0.00 & -1.01 & 0.63 \\
\hline $6 \mathrm{H}-39 \mathrm{~N}$ & 2.060 & 2.037 & 2.037 & 3.638 & 2.090 \\
\hline $6 \mathrm{H}-38 \mathrm{O}$ & 2.811 & 2.891 & 2.886 & 2.164 & 2.819 \\
\hline $6 \mathrm{H}-42 \mathrm{O}$ & 2.774 & 2.798 & 2.788 & 2.092 & 2.871 \\
\hline $6 \mathrm{H}-2 \mathrm{C}$ & 1.087 & 1.089 & 1.089 & 1.083 & 1.089 \\
\hline $39 N-36 S$ & 1.619 & 1.618 & 1.618 & 1.592 & 1.616 \\
\hline $39 \mathrm{~N}-40 \mathrm{~S}$ & 1.610 & 1.612 & 1.612 & 1.594 & 1.615 \\
\hline $36 \mathrm{~S}-37 \mathrm{O}$ & 1.449 & 1.448 & 1.448 & 1.447 & 1.447 \\
\hline $36 \mathrm{~S}-38 \mathrm{O}$ & 1.463 & 1.463 & 1.463 & 1.470 & 1.463 \\
\hline $40 \mathrm{~S}-410$ & 1.451 & 1.449 & 1.449 & 1.471 & 1.448 \\
\hline $40 \mathrm{~S}-42 \mathrm{O}$ & 1.463 & 1.464 & 1.464 & 1.449 & 1.463 \\
\hline $36 \mathrm{~S}-39 \mathrm{~N}-40 \mathrm{~S}$ & 127.4 & 127.5 & 127.6 & 128.9 & 127.7 \\
\hline $\mathrm{X}-6 \mathrm{H}-39 \mathrm{~N}-36 \mathrm{~S}$ & 122.8 & 164.0 & 141.6 & 78.3 & 14.2 \\
\hline
\end{tabular}

$X$ stands for the centroid of the imidazolium ring. Distances and angles are given in angstroms and degrees respectively. Relative energies to the conformer III are given in $\mathrm{kcal} / \mathrm{mol}$.

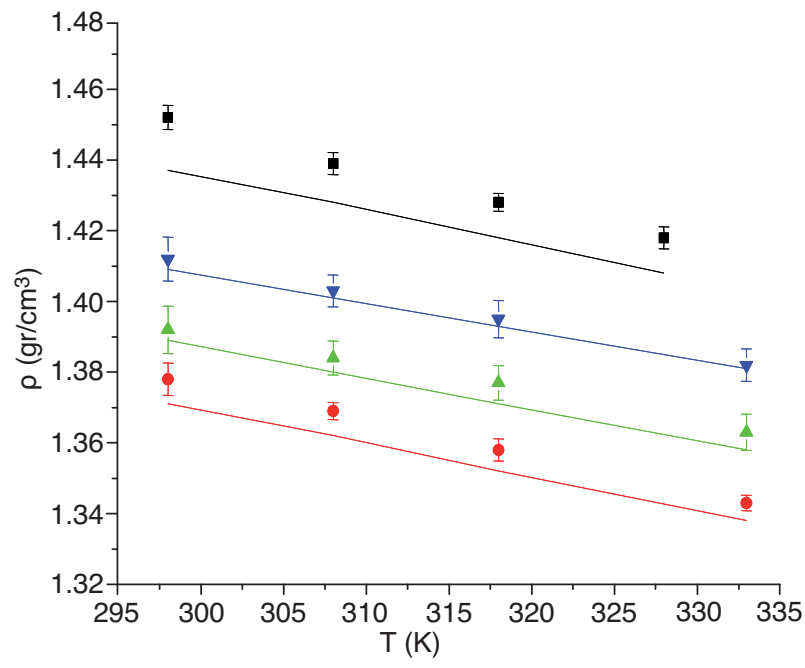

Figure 3

Experimental data (lines [48]) and MD simulation results (points) for the density of $\left[\mathrm{bmim}^{+}\right]\left[\mathrm{Tf}_{2} \mathrm{~N}^{-}\right]$at $0.1 \mathrm{MPa}$ (black) and $\left[\mathrm{hmim}^{+}\right]\left[\mathrm{Tf}_{2} \mathrm{~N}^{-}\right]$at $0.1 \mathrm{MPa}$ (red) $26 \mathrm{MPa}$ (green) and 60 MPa (blue).

methods are used in modeling the Coulombic potential in the force field (Tables A1 and A2 for $\left[\mathrm{bmim}^{+}\right]\left[\mathrm{Tf}_{2} \mathrm{~N}^{-}\right]$and $\left[\mathrm{hmim}^{+}\right]\left[\mathrm{Tf}_{2} \mathrm{~N}^{-}\right]$ion-pairs in the Appendix). Other authors have used the atomic charges only by taking into account the isolated geometries for both anion and cation [42].

\subsection{Molecular Simulation}

The model developed for the ILs was validated by comparing predicted volumetric and thermodynamic properties with available experimental data. Figure 3 shows the density variation of the two ILs with temperature and pressure. The experimental data are taken from Gomes de Azevedo et al. [48]. The $\left[\mathrm{hmim}^{+}\right]\left[\mathrm{Tf}_{2} \mathrm{~N}^{-}\right]$is shown to be more dense than $\left[\mathrm{bmim}^{+}\right]\left[\mathrm{Tf}_{2} \mathrm{~N}^{-}\right]$. Agreement between experimental data and simulation is very good and deviations are within

TABLE 2

Experimental data [48] and MD simulation results for the isothermal compressibility $\kappa_{T}=-\left(\frac{\partial V}{\partial P}\right)_{T} \frac{1}{V}$ of $\left[\mathrm{hmim}^{+}\right]\left[\mathrm{Tf}_{2} \mathrm{~N}^{-}\right]$at $0.1 \mathrm{MPa}$

\begin{tabular}{|c|c|c|}
\hline \multirow{2}{*}{ Temperature (K) } & \multicolumn{2}{|c|}{$\kappa_{T}\left(\mathrm{x} \quad 10^{5} \mathrm{~atm}^{-1}\right)$} \\
\hline & Expt [48] & Simulation \\
\hline 298 & 4.68 & $4.16 \pm 0.60$ \\
\hline 308 & 4.79 & $4.17 \pm 0.51$ \\
\hline 318 & 5.08 & $4.54 \pm 0.33$ \\
\hline 333 & 5.37 & $4.84 \pm 0.36$ \\
\hline
\end{tabular}


TABLE 3

Experimental data [48] and MD simulation results for the volume expansivity $a_{P}=\left(\frac{\partial V}{\partial T}\right)_{P} \frac{1}{V}$ of $\left[\mathrm{hmim}^{+}\right]\left[\mathrm{Tf}_{2} \mathrm{~N}^{-}\right]$at $298 \mathrm{~K}$

\begin{tabular}{c|c|c}
\hline \multirow{2}{*}{ Pressure (MPa) } & \multicolumn{2}{|c}{$a_{P}\left(\mathrm{x} 10^{4} \mathrm{~K}^{-1}\right)$} \\
\cline { 2 - 3 } & Expt [48] & Simulation \\
\hline 0.1 & 7.00 & $8.52 \pm 0.55$ \\
\hline 26 & 6.54 & $6.82 \pm 0.60$ \\
\hline 60 & 5.73 & $7.01 \pm 0.41$ \\
\hline
\end{tabular}

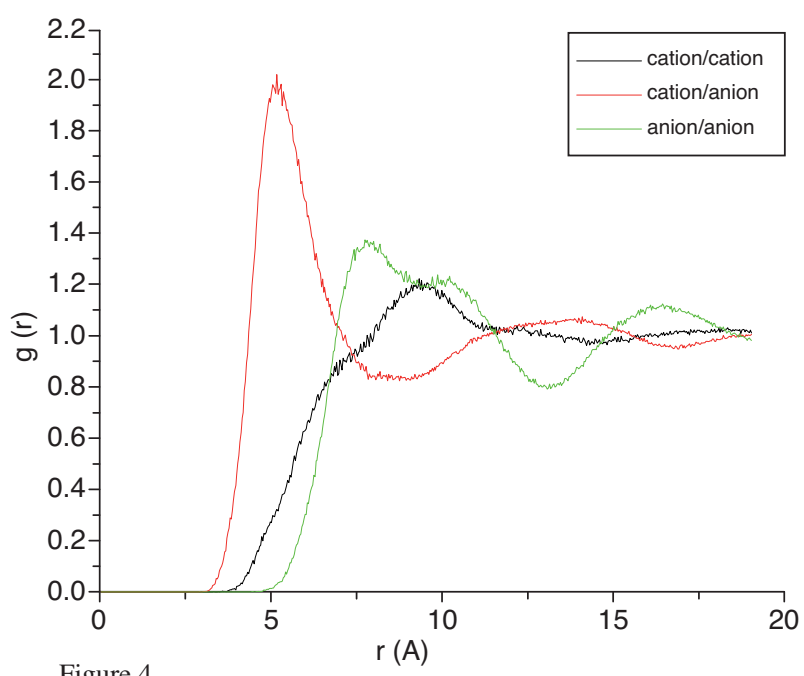

Figure 4

Center of mass (COM) radial distribution functions of the ions $\left[\mathrm{hmim}^{+}\right]$and $\left[\mathrm{Tf}_{2} \mathrm{~N}^{-}\right]$at $333 \mathrm{~K}$ and $0.1 \mathrm{MPa}$. less than $1 \%$ in all cases. It should be emphasized that calculations are pure predictions without any parameter adjustment. Thermodynamic properties such as the isothermal compressibility and the isobaric thermal expansivity were also evaluated and found to be in good agreement with available experimental data, as shown in Tables 2 and 3 for the case of $\left[\mathrm{hmim}^{+}\right]\left[\mathrm{Tf}_{2} \mathrm{~N}^{-}\right]$.

In order to evaluate the structural properties of the ILs, various radial distribution functions (RDFs) were calculated. The center-of-mass (COM) RDFs between all pairs of interacting ions present in the system, obtained from MD, are shown in Figure 4 at $333 \mathrm{~K}$ and ambient pressure. It is observed that ordering persists beyond $19 \AA$ as a result of the long-range Coulombic interactions present in the system. According to the RDF curve of the cation - anion pair a sharp peak is located at about $5.2 \AA$ and a weaker but broader peak at $13.4 \AA$. The anion - anion RDF shows a split peak at $7.8 \AA$ and $10.3 \AA$ which is due to the symmetric structure of the ion, while a second peak is observed at $16.4 \AA$. The cation - cation RDF curve exhibits a broad peak around 9.4 A.

Segmental dynamics of ILs was investigated through the reorientation of the bonds of the ions, as expressed by the second-order correlation function given by the expression:

$$
P_{2}(t)=\frac{1}{2}\left\{3\left\langle[\mathbf{u}(t) \cdot \mathbf{u}(0)]^{2}\right\rangle-1\right\}
$$

where $\mathbf{u}(0)$ and $\mathbf{u}(t)$ correspond to the orientation of a bond vector at time 0 and time $t$, respectively. In Figure 5, the second order autocorrelation function extracted from simulation trajectories for various bonds of the ion $\left[\mathrm{hmim}^{+}\right]$is shown. The bonds in the ring decorrelate slower than the bonds in
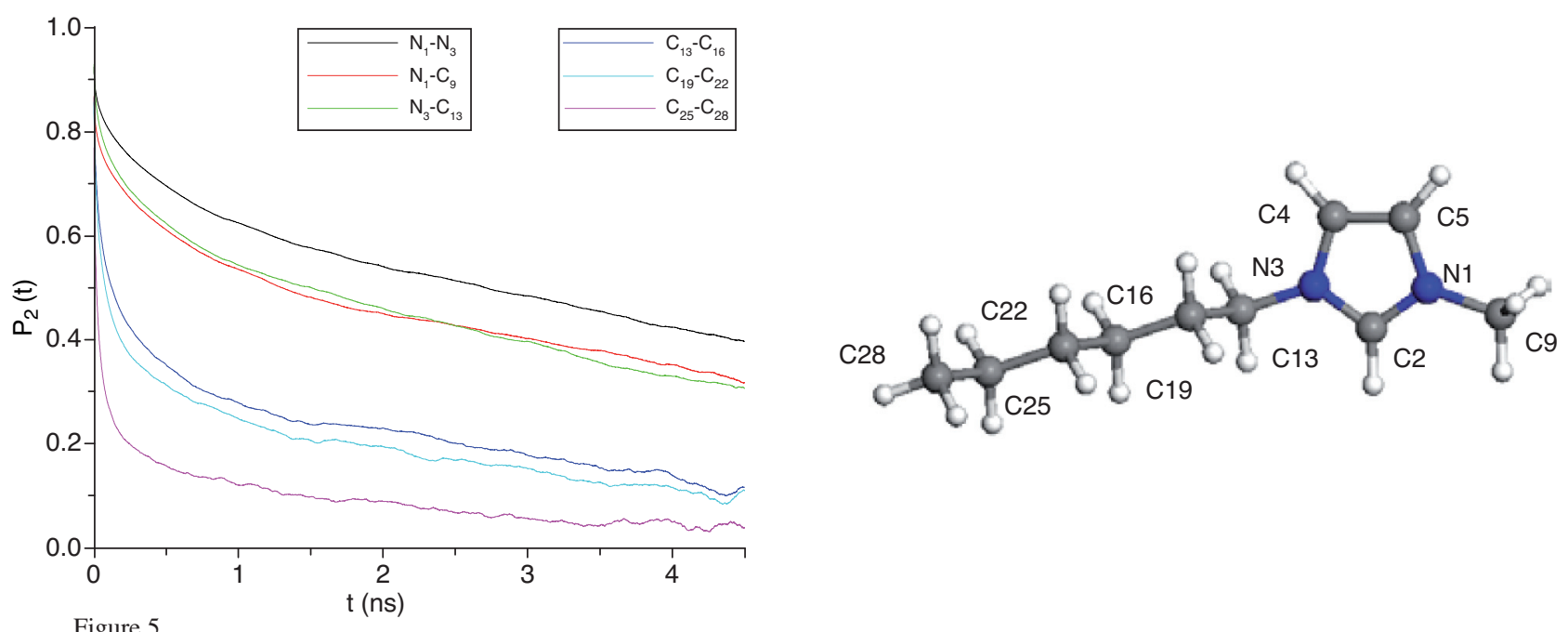

Figure 5

Decorrelation of various bonds of the $\left[\mathrm{hmim}^{+}\right]$ion of the $\left[\mathrm{hmim}^{+}\right]\left[\mathrm{Tf}_{2} \mathrm{~N}^{-}\right] \mathrm{IL}$ at $298 \mathrm{~K}$ and $0.1 \mathrm{MPa}$. 
alkyl chain of the cation. Furthermore, as one approaches the end of the alkyl chain bonds decorrelate faster. This is due to the fact that the alkyl chain can move more freely than the ring and, at the same time, the charges of the atoms close to the end of the alkyl chain are almost negligible. The bond vector orientation autocorrelation functions, $P_{2}(t)$ are described accurately by the modified Kohlrausch - Williams - Watts (mKWW) function:

$$
P_{m K W W}(t)=\alpha \exp \left[-\left(\frac{t}{\tau_{0}}\right)\right]+(1-\alpha) \exp \left[-\left(\frac{t}{\tau_{K W W}}\right)^{\beta}\right]
$$

that consists of a fast exponential decay with amplitude $\alpha$ and a slow KWW function related to the segmental motion of the IL [49]. In this way, the mean correlation times of bond orientational relaxation were evaluated at $298 \mathrm{~K}$ and found to be in the range of 1-10 ns for the cation (depending on the bond, as shown in Fig. 5) and an order of magnitude lower for the anion $\left[\mathrm{Tf}_{2} \mathrm{~N}^{-}\right]$.

$\mathrm{MD}$ configurations for ILs at various temperatures were used for the calculation of the Henry's law constant of $\mathrm{CO}_{2}$ in the IL using Widom's test particle insertion method, as described in Section 2. In Figure 6, experimental data [50] and molecular simulation predictions for $\mathrm{CO}_{2}$ in $\left[\mathrm{bmim}^{+}\right]\left[\mathrm{Tf}_{2} \mathrm{~N}^{-}\right]$are shown. Predictions using either of the two force fields for $\mathrm{CO}_{2}$ are in good agreement with experiments, although calculations with EPM2 force field are much closer to the data. Simulations for other ILs and for other solvents (primarily water) are under way.

\section{3 tPC-PSAFT Predictions and Correlations}

Recent representative calculations for a binary and a ternary IL mixture with IPC-PSAFT are discussed here. Calculations for a number of other mixtures can be found in [47]. Heintz et al. [51] VLE measurements for 1-octyl-3-methylimidazolium tetrafluoroborate $\left(\left[\mathrm{omim}^{+}\right]\left[\mathrm{BF}_{4}^{-}\right]\right)$with benzene show a change in sign of the temperature dependence of the activity coefficient of benzene. Despite this non-ideal behavior, tPC-PSAFT predictions at $298.15 \mathrm{~K}, 303.15 \mathrm{~K}, 308.15 \mathrm{~K}$ and $313.15 \mathrm{~K}$ are in excellent agreement with experimental data, as shown in Figure 7.

A more challenging mixture to model is the ternary $\mathrm{CO}_{2}-$ $\mathrm{H}_{2} \mathrm{O}-\left[\mathrm{bmim}^{+}\right]\left[\mathrm{NO}_{3}^{-}\right]$mixture. Initially, tPC-PSAFT was applied to correlate the VLE of $\mathrm{CO}_{2}-\mathrm{H}_{2} \mathrm{O}$ and $\mathrm{CO}_{2}-$ $\left[\mathrm{bmim}^{+}\right]\left[\mathrm{NO}_{3}{ }^{-}\right]$mixtures. Several combinations of pure component parameters with and without association between similar and dissimilar molecules were tested in order to represent all the available equilibrium data for the $\mathrm{CO}_{2}-\mathrm{H}_{2} \mathrm{O}$ mixture, including the minimum $\mathrm{H}_{2} \mathrm{O}$ concentration in the $\mathrm{CO}_{2}$-rich phase in the P-y diagram. This minimum occurs at pressures near the critical pressure of $\mathrm{CO}_{2}(73.773 \mathrm{bar})$ and is due to a phase transition from VLE to LLE [52]. Water was modeled as a 3-associating site fluid while $\mathrm{CO}_{2}$ was treated as a non self-associating fluid. In addition, cross-association between $\mathrm{CO}_{2}$ and $\mathrm{H}_{2} \mathrm{O}$ molecules was taken into account. Recently, Perakis et al. [52] found that the phase behavior of $\mathrm{CO}_{2}-\mathrm{H}_{2} \mathrm{O}$ mixture cannot be described with CPA or SAFT EoS by treating $\mathrm{CO}_{2}$ as a non-associating molecule. Our

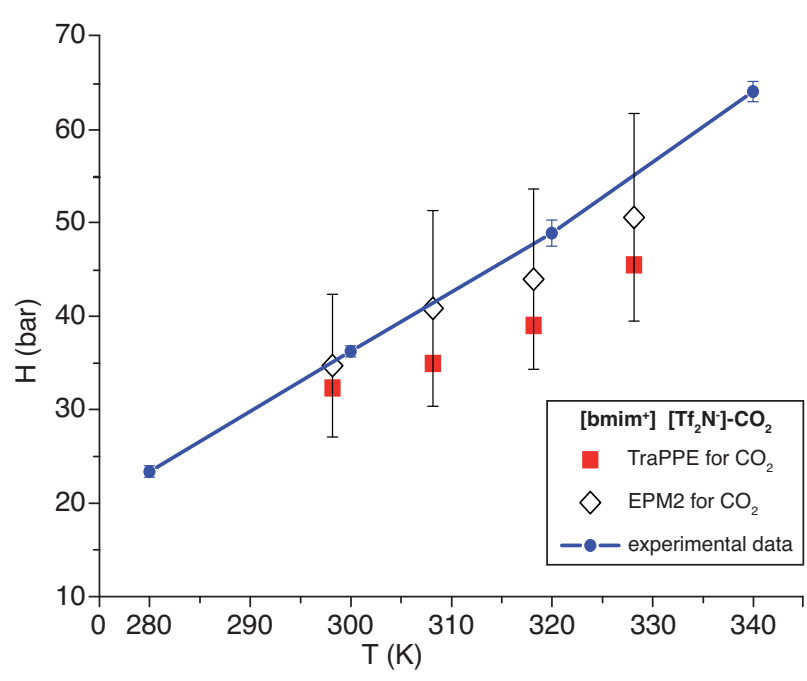

Figure 6

Henry's law constant of $\mathrm{CO}_{2}$ in $\left[\mathrm{bmim}^{+}\right]\left[\mathrm{Tf}_{2} \mathrm{~N}^{-}\right]$. Experimental data (blue squares and line from [50]) and molecular simulation predictions from TraPPE (red squares) and EPM2 model (open diamonds) for $\mathrm{CO}_{2}$.

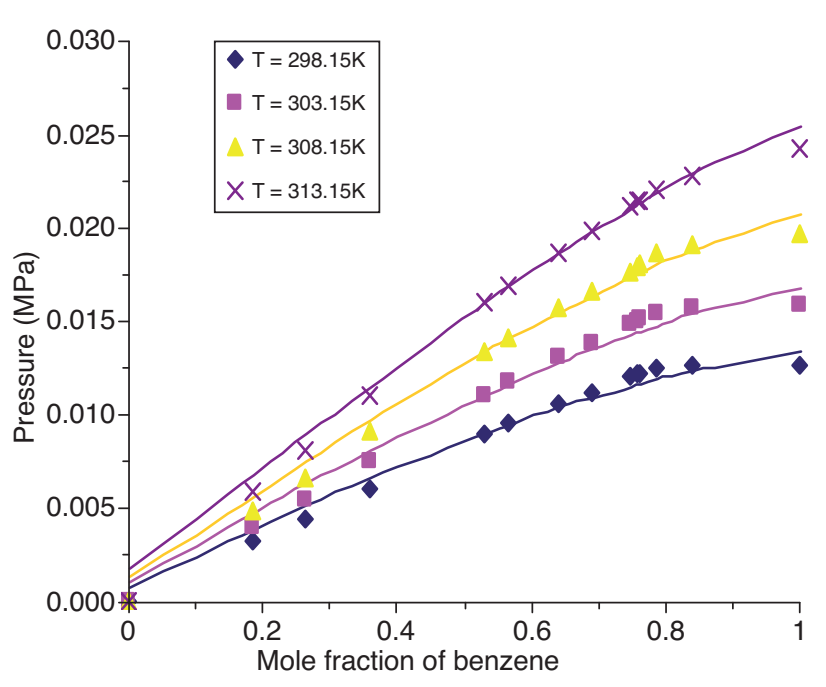

Figure 7

VLE pressure of benzene - $\left[\mathrm{omim}^{+}\right]\left[\mathrm{BF}_{4}^{+}\right]$mixture. Experimental data (points [51]) and tPC-PSAFT prediction (lines). 


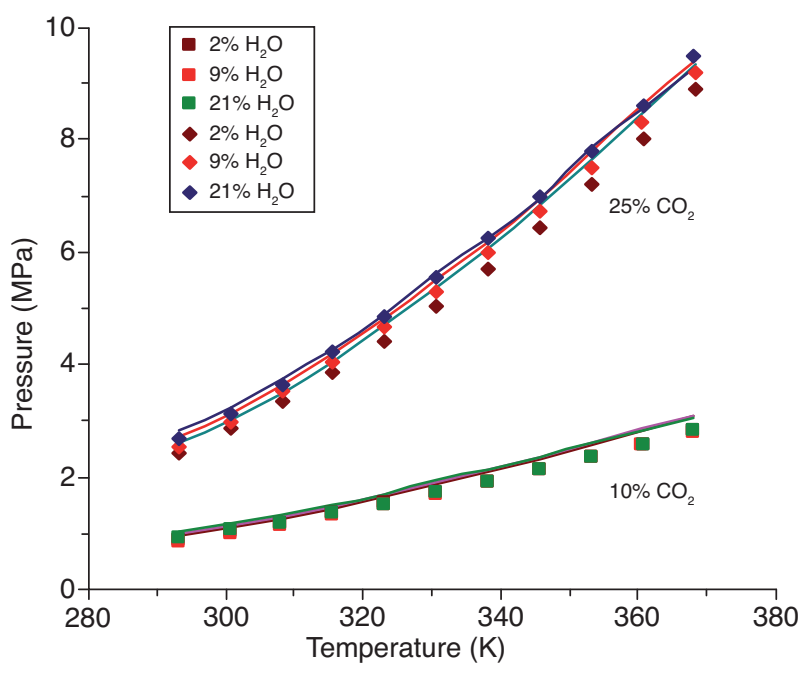

Figure 8

VLE pressure for $\mathrm{CO}_{2}-\mathrm{H}_{2} \mathrm{O}-\left[\mathrm{bmim}^{+}\right]\left[\mathrm{NO}_{3}^{-}\right]$. Experimental data (points) and tPC-PSAFT correlation (lines).

work showed the opposite, as long as quadrupolar interactions between $\mathrm{CO}_{2}$ molecules are considered explicitly.

Flow calorimetric measurements of Wormald et al. revealed that the enthalpy of association of water $(\mathrm{g})-\mathrm{CO}_{2}$ is $-14 \pm 2 \mathrm{~kJ} / \mathrm{mol}$ [53]. The hydrogen bonding energy of crossassociation of $1268.7 \mathrm{~K}$ used in our model corresponds to $\sim 10.6 \mathrm{~kJ} / \mathrm{mol}$. In addition, a binary interaction parameter $k_{\mathrm{H}_{2} \mathrm{O}-\mathrm{CO}_{2}}=0.2$ was used in the calculations.

$\left[\mathrm{bmim}^{+}\right]\left[\mathrm{NO}_{3}{ }^{-}\right]$was treated as a self-associating fluid with two associating sites, one for each ion. Cross-association between $\mathrm{H}_{2} \mathrm{O}$ and $\left[\mathrm{bmim}^{+}\right]\left[\mathrm{NO}_{3}{ }^{-}\right]$was also assumed and the experimentally measured enthalpy of $\mathrm{H}$-bonding equal to $5.0 \mathrm{~kJ} / \mathrm{mol}$ [54] was used, which corresponds to $\varepsilon_{\mathrm{hb}} / \mathrm{k}=$ $2416.5 \mathrm{~K}$. The association volume was taken to be equal to the association volume between water molecules, that is $\kappa_{[b m i m]\left[\mathrm{NO}_{3}\right]-\mathrm{H}_{2} \mathrm{O}}=\kappa_{\mathrm{H}_{2} \mathrm{O}-\mathrm{H}_{2} \mathrm{O}}=0.249$. The model was subsequently applied to the correlation of experimental data of the ternary $\mathrm{CO}_{2}-\mathrm{H}_{2} \mathrm{O}-\left[\mathrm{bmim}^{+}\right]\left[\mathrm{NO}_{3}{ }^{-}\right]$mixture. The $\mathrm{H}_{2} \mathrm{O}-$ $\left[\mathrm{bmim}^{+}\right]\left[\mathrm{NO}_{3}^{-}\right]$binary interaction parameter was fitted to ternary experimental data (no phase equilibrium data exist for this binary) and a linear dependence on temperature was found. Comparison between experimental data and tPCPSAFT correlation is shown in Figure 8. The agreement is good in all cases.

\section{CONCLUSIONS}

In this work, a spectrum of computational methods, that include ab initio DFT calculations, molecular atomistic simulations and a macroscopic equation of state, covering a broad range of length and time scales were employed to study the microscopic structure, the molecular dynamics and the macroscopic thermodynamic properties of various imidazolium-based ILs. The atomistic force field based on the CHARMM potential and the ab initio calculations were shown to provide accurate representation of IL volumetric properties and of $\mathrm{CO}_{2}$ solubility, in the temperature range of 298-338 K. IL molecules were found to exhibit relatively slow dynamics, in agreement with other similar studies from the literature. Finally, tPC-PSAFT was shown to correlate accurately the phase equilibria of a binary and of a ternary IL mixture with polar solvents. Additional work is needed towards the incorporation of explicit representation of electrostatic interactions between ions, in the case of an aqueous solvent. In summary, this work has shown that computational chemistry and molecular modeling methods can provide reliable information concerning the structure and physical properties of ILs, which is very valuable, especially in the absence of experimental data.

\section{ACKNOWLEDGMENT}

Financial support provided by INTAS through Research Project No. 05-1000008-8020 on Development of Sustainable Industrial Processes: Experimental, Theoretical and Computational Investigation of Thermodynamic Properties and Phase Equilibria of Ionic Liquid Mixtures is gratefully acknowledged. Javier Ramos thanks CSIC for financial support through an I3P tenure track position. The authors also acknowledge Centro Técnico de Informática (CTI-CSIC) and Centro de Investigaciones Energéticas, Medioambientales y Tecnológicas (CIEMAT) both in Madrid, Spain for the use of their computational resources for DFT and MD calculations. Finally, we are grateful to Dr. Loukas Peristeras of Scienomics SARL in Paris, France for the technical assistance provided regarding the MAPS software.

\section{REFERENCES}

1 Wasserscheid P., Welton T. (Eds.) (2003) Ionic Liquids in Synthesis, Wiley-VHC Verlag, Weinheim.

2 Earle M.J., Seddon K.R. (2000) Pure Appl.Chem. 72, 1391.

3 Brennecke J.F., Maginn E.J. (2001) AIChE J. 47, 2384.

4 Olivier-Bourbigou H., Magna L. (2002) J. Mol. Catal. A-Chem. 182-183, 419.

5 Blanchard L.A., Hancu D., Beckman E.J., Brennecke J.F. (1999) Nature 399, 28.

6 Blanchard L.A., Brennecke J.F. (2001) Ind. Eng. Chem. Res. 40, 287.

7 Blanchard L.A., Gu Z., Brennecke J.F. (2001) J. Phys. Chem. B 105, 2437.

8 Webb P.B., Sellin M.F., Kunene T.E., Williamson S., Slawin A.M.Z., Cole-Hamilton D.J. (2003) J. Am. Chem. Soc. 125, 15577. 
9 Cole-Hamilton D.J. (2003) Science 299, 1702.

10 Lozano P., De Diego T., Carrié D., Vaultier M., Iborra J.L. (2004) J. Mol. Catal. A-Chem. 214, 113.

11 Dzyuba S.V., Bartsch R.A. (2003) Angew.Chem. Int. Edit. 42, 148.

12 Reetz M.T., Wiesenhöfer W., Franciò G., Leitner W. (2003) Adv. Synth. Catal.345, 1221.

13 Brown R.A., Pollet P., McKoon E., Eckert C.A., Liotta C.L., Jessop P.G. (2001) J. Am. Chem. Soc. 123, 1254.

14 Anthony J.L., Anderson J.L., Maginn E.J., Brennecke J.F. (2005) J. Phys. Chem. B 109, 6366.

15 Husson-Borg P., Majer V., Costa Gomes M.F. (2003) J. Chem. Eng. Data 48, 480.

16 Shariati A., Peters C.J. (2004) J. Supercrit. Fluid. 29, 43.

17 Kroon M.C., Shariati A., Costantini M., Van Spronsen J., Witkamp G.J., Sheldon R.A., Peters C.J. (2005) J. Chem. Eng. Data 50, 173.

18 Shariati A., Peters C.J. (2005) J. Supercrit. Fluid.34, 171.

19 Seddon K.R, Stark A., Torres M.-J. (2000) Pure Appl. Chem.72, 2275.

20 Zhang S., Li X., Chen H., Wang J., Zhang J., Zhang M. (2004) J. Chem. Eng. Data 49, 760.

21 López-Pastor M., Ayora-Cañada M.J., Valcárcel M., Lendl B. (2006) J. Phys. Chem. B 110, 10896.

22 Katayanagi H., Nishikawa K., Shimozaki H., Miki K., Westh P., Koga Y. (2004) J. Phys. Chem. B 108, 19451.

23 Jork C., Seiler M., Beste Y.-A., Arlt W. (2004) J. Chem. Eng. Data 49, 852 .

24 Hanke C.G., Price S.L., Lynden-Bell R.M. (2001) Mol. Phys. 99, 801 .

25 Liu Z., Huang S., Wang W. (2004) J. Phys. Chem. B 108, 12978. 26 Morrow T.I., Maginn E.J. (2002) J. Phys. Chem. B 106, 12807.

27 Shah J.K., Maginn E.J. (2005) J. Phys. Chem. B 109, 10395.

28 Urukova I., Vorholz J., Maurer G. (2005) J. Phys. Chem. B 109, 12154 (corrections: ibid (2006) 110, 18072).

29 Huang X., Margulis C.J., Li Y., Berne B.J. (2005) J. Am. Chem. Soc. 127, 17842 .

30 Belvèze L.S., Brennecke J.F., Stadtherr M.A. (2004) Ind. Eng. Chem. Res. 43, 815.

31 Rebelo L.P.N., Najdanovic-Visak V., Visak Z.P., Nunes da Ponte M., Szydlowski J., Cerdeiriña C.A., Troncoso J., Romaní L., Esperança J.M.S.S., Guedes H.J.R., De Sousa H.C. (2004) Green Chem. 6, 369.

32 Banerjee T., Singh M.K., Kumar Sahoo R., Khanna A. (2005) Fluid Phase Equilibr. 234, 64.

33 Karakatsani E.K., Spyriouni T., Economou I.G. (2005) AIChE J. $\mathbf{5 1 ,} 2328$.

34 Karakatsani E.K., Economou I.G. (2006) J. Phys. Chem. B 110,9252 .
35 Gaussian 03, Revision B.05, Frisch M.J., Trucks G.W., Schlegel H.B., Scuseria G.E., Robb M.A., Cheeseman J.R., Montgomery Jr. J.A., Vreven T., Kudin K.N., Burant J.C., Millam J.M., Iyengar S.S., Tomasi J., Barone V., Mennucci B., Cossi M., Scalmani G., Rega N., Petersson G.A., Nakatsuji H., Hada M., Ehara M., Toyota K., Fukuda R., Hasegawa J., Ishida M., Nakajima T., Honda Y., Kitao O., Nakai H., Klene M., Li X., Knox J.E., Hratchian H.P., Cross J.B., Bakken V., Adamo C., Jaramillo J., Gomperts R., Stratmann R.E., Yazyev O., Austin A.J., Cammi R., Pomelli C., Ochterski J.W., Ayala P.Y., Morokuma K., Voth G.A., Salvador P., Dannenberg J.J., Zakrzewski V.G., Dapprich S., Daniels A.D., Strain M.C., Farkas O., Malick D.K., Rabuck A.D., Raghavachari K., Foresman J.B., Ortiz J.V., Cui Q., Baboul A.G., Clifford S., Cioslowski J., Stefanov B.B., Liu G., Liashenko A., Piskorz P., Komaromi I., Martin R.L., Fox D.J., Keith T., Al-Laham M.A., Peng C.Y., Nanayakkara A., Challacombe M., Gill P.M.W., Johnson B., Chen W., Wong M.W., Gonzalez C., Pople J.A., Gaussian Inc., Wallingford CT.

36 Becke A.D. (1992) J. Chem. Phys. 96, 2155.

37 Lee C., Yang W., Parr R G. (1998) Phys. Rev. B 37, 785.

38 Breneman C.M., Wiberg K.B. (1990) J. Comp. Chem. 11, 361.

39 More information can be found at: www.scienomics.com.

40 Kale L., Skeel R., Bhandarkar M., Brunner R., Gursoy A., Krawetz N., Phillips J., Shinozaki A., Varadarajan K., Schulten K. (1999) J. Comput. Phys. 151, 283.

41 Cadena C., Zhao Q., Snurr R.Q., Maginn E.J. (2006) J. Phys. Chem. 110, 2821.

42 Cadena C., Maginn E.J. (2006) J.Phys. Chem. B 110, 18026.

43 Widom B. (1963) J. Chem. Phys. 39, 2808.

44 Potoff J.J., Siepmann J.I. (2001) AIChE J. 47, 1676.

45 Harris J., Yung K. (1995) J. Phys. Chem. 99, 12021.

46 Kumełan J., Pérez-Salado Kumps Á., Urukova I., Tuma D., Maurer G. (2005) J. Chem. Thermodyn. 37, 595 (corrections: ibid (2007) 39, 335).

47 Karakatsani E.K., Economou I.G., Kroon M.C., Peters C.J., Witkamp G.-J. (2007) J. Phys. Chem. C 111, 15487.

48 Gomes de Azevedo R., Esperanca J.M.S.S., Szydlowski J., Visak Z.P., Pires P.F., Guedes H.J.R., Rebelo L.P.N. (2005) J. Chem. Thermodyn. 37, 888 .

49 Doxastakis M., Theodorou D.N., Fytas G., Kremer F., Faller R., Müller-Plathe F., Hadjichristidis N. (2003) J. Chem. Phys. 119, 6883.

50 Lee B.-C., Outcalt S.L. (2006) J. Chem. Eng. Data 51, 892.

51 Safarov J., Verevkin S.P., Bich E., Heintz A. (2006) J. Chem. Eng. Data 51, 518.

52 Perakis C., Voutsas E., Magoulas K., Tassios D. (2006) Fluid Phase Equilibr. 243, 142.

53 Wormald C.J., Colling C.N., Sellars A.J. (1983) Thermodynamic properties of gaseous mixtures containing water. Proceedings of the International Gas Research Conference 1983, p. 1070.

54 Cammarata L., Kazarian S.G., Salter P.A., Welton T. (2001) Phys. Chem. Chem. Phys. 3, 5192.

Final manuscript received in November 2007 Published online in May 2008 or distributed for profit or commercial advantage and that copies bear this notice and the full citation on the first page. Copyrights for components of this work owned by others than IFP must be honored. Abstracting with credit is permitted. To copy otherwise, to republish, to post on servers, or to redistribute to lists, requires prior specific permission and/or a fee: Request permission from Documentation, Institut français du pétrole, fax. +33147527078 , or revueogst@ifp.fr. 
IG Economou et al. / Multi-scale Modeling of Structure, Dynamic and Thermodynamic Properties of Imidazolium-based Ionic Liquids: Ab initio DFT Calculations, Molecular Simulation and Equation of State Predictions

\section{APPENDIX}

TABLE A1

Electrostatic charges for $\left[\mathrm{bmim}^{+}\right]\left[\mathrm{Tf}_{2} \mathrm{~N}^{-}\right]$conformers. Numbering is given in Figure 2 .

\begin{tabular}{|c|c|c|c|c|c|c|c|}
\hline & bmim & 1 & 2 & 3 & 4 & 5 & Mean \\
\hline 1 & $\mathbf{N}$ & - & - & 0.159956 & 0.116197 & 0.169756 & 0.1526764 \\
\hline 2 & C & - & - & 0.013732 & 0.028483 & -0.011097 & 0.01217 \\
\hline 3 & $\mathbf{N}$ & - & - & 0.028229 & 0.133752 & 0.092792 & 0.0631456 \\
\hline 4 & $\mathrm{C}$ & - & - & -0.179122 & -0.193677 & -0.201419 & -0.1864734 \\
\hline 5 & C & - & - & -0.15647 & -0.167767 & -0.158658 & -0.1593148 \\
\hline 6 & $\mathbf{H}$ & - & - & 0.209 & 0.182203 & 0.20887 & 0.2031378 \\
\hline 7 & $\mathbf{H}$ & - & - & 0.206071 & 0.204892 & 0.209838 & 0.2064304 \\
\hline 8 & $\mathbf{H}$ & - & - & 0.179767 & 0.188986 & 0.188974 & 0.183551 \\
\hline 9 & C & - & - & -0.193866 & -0.116 & -0.259711 & -0.191246 \\
\hline 10 & $\mathbf{H}$ & - & - & 0.121273 & 0.089059 & 0.114 & 0.1134102 \\
\hline 11 & $\mathbf{H}$ & - & - & 0.153499 & 0.126298 & 0.228284 & 0.1630184 \\
\hline 12 & $\mathbf{H}$ & - & - & 0.089977 & 0.089467 & 0.110179 & 0.0938578 \\
\hline 13 & C & - & - & 0.087855 & -0.088733 & 0.033089 & 0.0412522 \\
\hline 14 & H & - & - & 0.025024 & 0.05903 & 0.041462 & 0.0350254 \\
\hline 15 & $\mathbf{H}$ & - & - & 0.03962 & 0.067608 & 0.012784 & 0.0395018 \\
\hline 16 & C & - & - & 0.071072 & 0.167616 & 0.056635 & 0.0883512 \\
\hline 17 & $\mathbf{H}$ & - & - & -0.045262 & -0.052316 & -0.033383 & -0.0445734 \\
\hline 18 & $\mathbf{H}$ & - & - & 0.023318 & -0.040171 & 0.012688 & 0.0080662 \\
\hline 19 & C & - & - & 0.20203 & 0.229861 & 0.241052 & 0.2155126 \\
\hline 20 & $\mathbf{H}$ & - & - & -0.012868 & -0.021181 & -0.024967 & -0.0168906 \\
\hline 21 & $\mathbf{H}$ & - & - & -0.048587 & -0.061666 & -0.052389 & -0.051899 \\
\hline 22 & $\mathrm{C}$ & - & - & -0.256062 & -0.266437 & -0.291098 & -0.2660022 \\
\hline 23 & $\mathbf{H}$ & - & - & 0.060479 & 0.067524 & 0.069366 & 0.0639314 \\
\hline 24 & $\mathbf{H}$ & - & - & 0.049922 & 0.046475 & 0.056639 & 0.0507952 \\
\hline 25 & $\mathbf{H}$ & - & - & 0.067816 & 0.070337 & 0.074322 & 0.0697996 \\
\hline 26 & C & - & - & 0.353348 & 0.554233 & 0.36853 & 0.3986496 \\
\hline 27 & $\mathbf{F}$ & - & - & -0.130199 & -0.184036 & -0.135088 & -0.1426054 \\
\hline 28 & $\mathbf{F}$ & - & - & -0.174618 & -0.22484 & -0.166801 & -0.1837048 \\
\hline 29 & $\mathbf{F}$ & - & - & -0.152061 & -0.184106 & -0.161105 & -0.1609124 \\
\hline 30 & $\mathbf{S}$ & - & - & 1.176669 & 1.113662 & 1.17948 & 1.165888 \\
\hline 31 & O & - & - & -0.532375 & -0.531883 & -0.539707 & -0.5343932 \\
\hline 32 & $\mathbf{O}$ & - & - & -0.578746 & -0.596424 & -0.557502 & -0.5784812 \\
\hline 33 & $\mathbf{N}$ & - & - & -0.789144 & -0.746376 & -0.791022 & -0.7810632 \\
\hline 34 & $\mathbf{S}$ & - & - & 1.105215 & 1.175217 & 1.127908 & 1.1238738 \\
\hline 35 & O & - & - & -0.511602 & -0.533786 & -0.514816 & -0.516728 \\
\hline 36 & O & - & - & -0.61069 & -0.628437 & -0.649458 & -0.6221234 \\
\hline 37 & $\mathrm{C}$ & - & - & 0.511914 & 0.464147 & 0.532687 & 0.5065622 \\
\hline 38 & $\mathbf{F}$ & - & - & -0.192532 & -0.16283 & -0.199178 & -0.188006 \\
\hline 39 & $\mathbf{F}$ & - & - & -0.191721 & -0.159894 & -0.190894 & -0.185212 \\
\hline 40 & $\mathbf{F}$ & - & - & -0.179861 & -0.21449 & -0.191041 & -0.1889782 \\
\hline
\end{tabular}

TABLE A2

Electrostatic charges for $\left[\mathrm{hmim}^{+}\right]\left[\mathrm{Tf}_{2} \mathrm{~N}^{-}\right]$conformers. Numbering is given in Figure 2.

\begin{tabular}{|c|c|c|c|c|c|c|c|}
\hline & nim & 1 & 2 & 3 & 4 & 5 & an \\
\hline & $\mathbf{N}$ & & & 81 & & & \\
\hline & $\mathbf{C}$ & & & & & & \\
\hline & $N$ & & & & & & \\
\hline & $\bar{C}$ & & & & & & \\
\hline & $\mathrm{C}$ & & & & & & \\
\hline & H & & & & & & \\
\hline & $\overline{\mathbf{H}}$ & & & & & & \\
\hline & $\overline{\mathbf{H}}$ & & & & & & \\
\hline & C & & & & & & \\
\hline & $\mathbf{H}$ & 7400 & 38 & 519 & & & \\
\hline & $\mathbf{H}$ & & 18 & & & & \\
\hline & $\mathbf{H}$ & 56 & 87 & 87 & & & \\
\hline & $\bar{C}$ & 9309 & 24 & 24 & & & \\
\hline & $\mathrm{H}$ & 0622 & 07944 & 211 & & & \\
\hline & H & & 017067 & 817 & & & \\
\hline & C & 01 & 26631 & & & & \\
\hline & $\mathbf{H}$ & & & & & & \\
\hline & $\mathbf{H}$ & & & & & & \\
\hline & & & & & & & \\
\hline & H & 20 & $\overline{007149}$ & 64 & & & \\
\hline & $\overline{\mathbf{H}}$ & & 028457 & & & & \\
\hline & C & & 047660 & & & & \\
\hline & $\mathrm{H}$ & & -0.013635 & 32 & 42 & & \\
\hline & H & 24745 & 0.020277 & & & 804 & \\
\hline & $\bar{C}$ & & & & & & \\
\hline & $\overline{\mathbf{H}}$ & & 47 & & & & \\
\hline & $\overline{\mathbf{H}}$ & & 10634 & & & & \\
\hline & C & & & & & & \\
\hline & H & & 06 & & & & \\
\hline & H & & 24 & & & & \\
\hline & $\mathbf{C}$ & & & & & & \\
\hline & H & & & & & & \\
\hline & H & & 26 & & & & \\
\hline & C & 329 & 40 & 770 & & & \\
\hline & H & & & & & & \\
\hline & H & & & & & & \\
\hline & H & & & & & & \\
\hline & C & & & & & & \\
\hline & I & & & & & & \\
\hline & $\mathbf{F}$ & & & & & & \\
\hline & F & & & & & & \\
\hline & $\mathbf{S}$ & & & & & & \\
\hline & $\overline{0}$ & & & & & & \\
\hline & $\overline{0}$ & & & & & & \\
\hline & $\bar{N}$ & & & & & & \\
\hline & $\mathbf{S}$ & & & & & & \\
\hline & 0 & & & & & & \\
\hline & 0 & & & & & & \\
\hline & C & & & & & & \\
\hline & F & & & & & & \\
\hline & $\mathbf{F}$ & & & & & & \\
\hline & & & & & & & \\
\hline
\end{tabular}

